\title{
Peningkatan Keterampilan Proses Sains Terpadu Siswa melalui Implementasi Levels of Inquiry (LoI)
}

\author{
Riski Muliyani ${ }^{1}$, Yudi Kurniawan ${ }^{2}$, Desvika Annisa Sandra ${ }^{3}$ \\ ${ }^{1,2,3}$ Program Studi Pendidikan Fisika STKIP Singkawang. Email: yudikurniawan1012@gmail.com
}

Diterima: 20 September 2017. Disetujui: 30 Oktober 2017. Dipublikasikan: Desember 2017

\begin{abstract}
The scientific process skills should trains to a pre-service teacher, especially pre-service physics teacher. This study aims to get description about the enhancement of students' integrated scientific process skill through the level of inquiry (LoI) learning model. This research located at a public junior high school in Singkawang City. This research use week experimental design with one group pretest-posttest design. Samples were taken by using cluster random technique. The instrument of collection data are tested KPS (scientific process skill test), LoI's observation sheets, and attitude scale sheet (to collect students' responses to LoI models). The result showed that students' integrated scientific process skill is enhanced in $n$-gain 0,31 (medium), LoI's observation sheet is"all activities were held" an attitude scale is 80,4\% (positive response). These could be concluded that Scientific Process Skill on that schools is enhancing (medium category) by using implementation of LoI model.
\end{abstract}

\begin{abstract}
Abstrak
Keterampilan Proses Sains (KPS) perlu dilatihkan terutama untuk calon guru sains termasuk calon guru fisika. Penelitian ini bertujuan untuk mendapatkan gambaran peningkatan aspek keterampilan proses sains (KPS) terpadu siswa melalui penerapan model Levels of Inquiry (LoI). Penelitian ini dilakukan di salah satu SMP Negeri Kota Singkawang, menggunakan metode weak experimental design dengan one group pretest-posttest design. Teknik pengambilan sampel menggunakan cluster random sampling. Instrument pengumpul data yang dipakai antara lain tes KPS, lembar observasi keterlaksanaan LoI, dan lembar skala sikap untuk mendapatkan deskripsi tanggapan siswa terhadap model LoI yang telah mereka alami. Hasil pengolahan instrument tes menunjukkan bahwa KPS yang dimiliki oleh siswa mengalami peningkatan dengan skor n-gain sebesar 0,31 (kategori sedang) dan keterlaksaaan model pembelajaran LOI dalam kategori "semua kegiatan siswa terlaksana" serta skala sikap dengan capaian respon bernilai 80,4\% (kategori positif). Dapat disimpulkan pada sekolah tersebut, KPS dapat ditingkatkan melalui penerapan LoI dengan kategori sedang.
\end{abstract}

Kata kunci: Keterampilan Proses Sains, Levels of Inquiry (LoI), Peningkatan

\section{PENDAHULUAN}

Proses pembelajaran sains yang ideal ialah menggunakan metode eksperimen dimana pola interaksi siswa dengan materi berupa pengalaman belajar langsung. Selain itu untuk menilai baik tidaknya kualitas suatu pembelajaran, dapat dilihat dari strategi pembelajaran yang digunakan, penggunaan model atau metode dalam proses belajar mengajar akan mempengaruhi proses pembelajaran itu sendiri (Irwandani, 2014; Irwandani \&
Rofiah, 2015). Konsep ini berbeda dengan fakta di sekolah dimana siswa sangat kurang aktif dalam proses pembelajaran (teacher centered). Dalam hal ini dapat diduga bahwa skenario pembelajaran belum melatihkan keterampilan proses sains (KPS) dan soal yang diberikan belum kontekstual sehingga hasil yang diperoleh siswa rendah (Ambarsari, Santosa, \& Maridi, 2013). Padahal, dalam proses pembelajarannya sains seharusnya tidak hanya tentang mendengarkan 
penjelasan dari guru semata, tetapi justru akan lebih baik jika siswa dilatih untuk menemukan konsep secara mandiri (Dewi, 2016).

KPS merupakan adaptasi dari keterampilan yang digunakan oleh para ilmuwan untuk menyusun suatu konsep, menyelidiki suatu masalah dan membuat kesimpulan atas masalah tersebut (Evriani, Kurniawan, \& Muliyani, 2017; Yusuf \& Wulan, 2015). Keterampilan proses didapatkan dengan melakukan suatu pendekatan pengajaran yang memberi kesempatan kepada siswa untuk ikut mengahayati proses penemuan atau penyusunan suatu konsep (Malik, Y. Kurnia, \& S. Robiatus, 2016). Selain itu berbagai kecakapan hidup seperti kemampuan mengamati, berpikir, bekerja, bersikap ilmiah dan berkomunikasi juga merupakan bagian dari Keterampilan Proses Sains (KPS) (Komikesari, 2016).

Setiap orang diharapkan memiliki KPS karena KPS sangat applicable dalam keseharian. Penerapannya tidak hanya dalam lingkup ilmuwan/saintis melainkan dalam lingkup aplikasi yang luas. Proses menyusun suatu gagasan/konsep, menyelidiki suatu permasalahan, menentukan alternatif solusi, serta menyimpulkan permasalahan tersebut dapat dilakukan oleh siapa saja. Oleh karena itu, KPS perlu dimiliki setiap siswa sebagai bekal hidup dimasyarakat (Ambarsari et al., 2013; Evriani et al., 2017).

Keterampilan ini dapat dibagi menjadi dua jenis, yaitu tingkat dasar dan terpadu. Adapun terdapat dua jenis KPS, yaitu KPS dasar dan KPS terpadu. Penelitian ini memfokuskan pada aspek KPS terpadu. KPS terpadu merupakan keterampilan yang memberdayakan siswa untuk menjawab pertanyaan mereka sendiri dan siswa dapat menafsirkan apa yang mereka amati, serta merancang eksperimen untuk menguji ide mereka sendiri (Evriani et al., 2017).
Dalam penelitian ini, data awal yang dipakai adalah hasil prariset yang diadakan di salah satu SMP Negeri di Kota Singkawang. Rendahnya keterampilan proses sains siswa tersebut disebabkan pembelajaran yang menggunakan metode informatif, dimana para guru di sekolah-sekolah lebih menitik beratkan pada kemampuan kognitif sehingga metode yang digunakan tidak relevan dengan pembelajaran fisika yang menekankan pada pemberian pengalaman langsung (Rusmiyati \& Yulianto, 2009).

Untuk mengatasi hal tersebut solusi yang dilakukan ialah dengan menerapkan model pembelajaran levels of inquiry (LoI) disetiap aktivitas di dalam kelas. Model LoI merupakan pembelajaran yang melibatkan siswa secara aktif sehingga berpeluang untuk mengembangkan keterampilan dalam proses intelektual dan ilmiah dengan lebih luas sehingga memperoleh capaian pembelajaran atau learning outcome yang diharapkan (Abdurrahman, 2017; Smallhorn, Young, Hunter, \& Burke da Silva, 2015). Inkuiri adalah kegiatan siswa yang menuntut siswa untuk mengembangkan pengetahuan dan pemahaman akan gagasan ilmiah, serta pemahaman tentang bagaimana ilmuan memahami alam (Rismawati, Sinon, Yusuf, \& Widyaningsih, 2017; Sasmita, 2017).

Model pembelajaran inkuiri mendorong siswa membangun pemahaman yang mendalam tentang konsep-konsep target yang hampir seluruhnya melalui pengalaman dan penalaran mereka sendiri (Loverude, Gonzalez, \& Nanes, 2011). Kegiatan yang dilakukan oleh siswa mencerminkan proses seperti yang dilakukan seorang ilmuwan dalam menciptakan pengetahuan baru (Lindsey, Hsu, Sadaghiani, Taylor, \& Cummings, 2012).

Berdasarkan penelitian Arief (2015), model pembelajaran LoI dapat meningkatkan KPS terpadu karena dapat 
mengembangkan kemampuan intelektual dan keterampilan proses sains secara sistematis. Semakin tinggi tahapan inkuiri maka semakin tinggi juga kemampuan intelektual siswa. Semakin tinggi kemampuan intelektual siswa maka keterlibatan guru juga semakin rendah. Dengan kata lain, siswa semakin aktif dalam mengambil peran ketika proses pembelajaran didasarkan pada penyelidikan ilmiah.

Berdasarkan uraian tersebut, studi ini ingin mendapatkan gambaran sejauh mana peningkatan KPS yang mampu "tercover" dalam model LoI.

\section{METODE PENELITIAN}

Penelitian ini merupakan penelitian kuantitatif dengan menggunakan metode weak experimental design dengan desain one group pretest-posttest. Teknik pengumpulan data yang digunakan dalam penelitian ini yaitu tes dan non tes.

Tes yang digunakan untuk mengukur KPS ialah tes KPS terpadu dalam bentuk pilihan ganda beralasan (15 butir), sedangkan instrumen non tes yang digunakan yaitu berupa lembar observasi keterlaksanaan model pembelajaran levels of inquiry (LoI) dan skala sikap untuk mengetahui respon siswa terhadap model pembelajaran LoI.

Dalam penelitian ini terdapat 15 soal KPS terpadu yang diberikan kepada siswa, dengan menggunakan distribusi data mengenai per aspek KPS dan nomor soal seperti pada Tabel 1 .

Tabel 1. Distribusi Aspek KPS Terpadu

\begin{tabular}{ccc}
\hline No & Aspek KPS & No Soal \\
\hline 1 & Merencanakan Penelitian & $7,9,12$ \\
2 & Melakukan Penelitian & $8,10,13$ \\
3 & Menafsirkan data & $4,5,6$ \\
4 & Mengajukan Hipotesis & $1,2,3$ \\
5 & Menerapkan Konsep & $11,14,15$ \\
\hline
\end{tabular}

Aspek KPS terpadu tersebut kemudian didistribusikan ke beberapa pertanyaan yang akan diberikan kepada siswa. Setelah data terkumpul, data dianalisis menggunakan uji gain ternormalisasi (n-gain) yang dapat dilihat pada formula berikut :

$$
\langle g\rangle=\frac{\text { posttest }- \text { pretest }}{\text { skor }_{\text {maks }}-\text { pretest }}
$$

Dengan persentase $\langle\mathrm{g}>$ yang digunakan untuk menentukan seberapa besar peningkatan KPS terpadu siswa yang dapat dilihat pada Tabel 2 .

Tabel 2. Interval Gain Ternormalisasi

\begin{tabular}{cc}
\hline Indeks gain & Kategori \\
\hline$<g>\geq 0_{x} 7$ & Tinggi \\
$0,3 \leq<g><0_{x} 7$ & Sedang \\
$<g><0_{x} 3$ & Rendah \\
\hline
\end{tabular}

(Hake, 1998).

Untuk langkah-langkah pembelajaran, LoI memiliki beberapa tahapan diantaranya (Erlinda, 2016; Ertikanto, 2017; Latifah, Setiawati, \& Basith, 2016)

\section{Observation}

Siswa mengamati fenomena, kemudian menjelaskan secara rinci apa yang mereka lihat, kemudian menemukan contoh-contoh lain dari fenomena

\section{Manipulation}

Siswa membuat rencana untuk mengumpulkan data kualitatif dan kuantitatif, kemudian menjalankan rencana tersebut.

3. Generalization

Siswa membuat prinsip-prinsip baru dan memberikan penjelasan yang masuk akal dari fenomena tersebut.

4. Verification

Siswa membuat prediksi dan melakukan pengujian menggunakan prinsip-prinsip yang telah ditentukan sebelumnya.

5. Application

Siswa membuat kesimpulan dari penyelidikan tersebut, kemudian guru membenarkan hal-hal yang kurang tepat. 


\section{HASIL DAN PEMBAHASAN}

Penelitian ini dilakukan untuk mengamati dan melihat adanya peningkatan keterampilan proses sains (KPS) terpadu siswa melalui penerapan model levels of inquiry (LoI). Untuk lebih ringkasnya, dapat dilihat pada Gambar 1 yang memperlihatkan detail peningkatan aspek KPS.

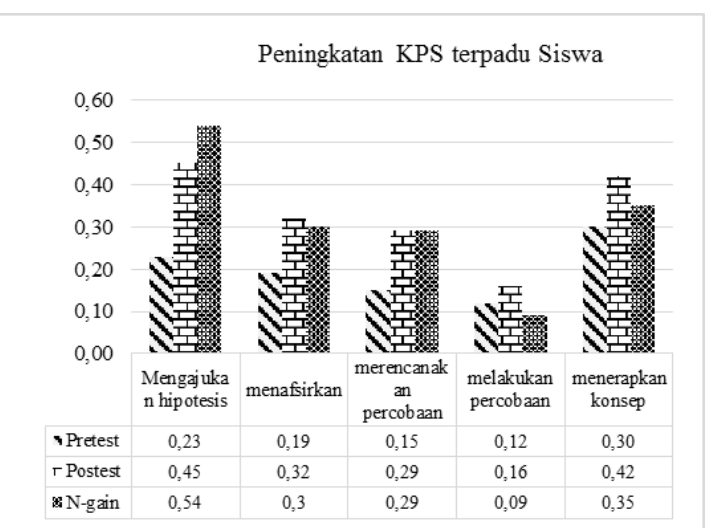

Gambar 1. Peningkatan KPS per Aspek setelah dinormalisasi

Berdasarkan Gambar 1, terlihat bahwa setiap aspek KPS terpadu mengalami peningkatan setelah diterapkan model LoI. Hal tersebut dapat dilihat dari hasil post-test siswa. Peningkatan KPS terpadu yang paling tinggi terdapat pada aspek mengajukan hipotesis sebesar 0,45 dan aspek KPS terpadu yang mengalami peningkatan terendah yaitu melakukan percobaan sebesar 0,16.

Penelitian ini menunjukkan bahwa LoI dapat meningkatkan KPS terpadu siswa dengan hasil rata-rata analisis ngain sebesar 0,31 dengan kategori sedang.

Peningkatan terbesar pada KPS terpadu berdasarkan uji n-gain ialah pada aspek mengajukan hipotesis sebesar 0,54. Hasil ini diduga karena sebelum siswa membuat hipotesis, peneliti selalu memberikan pertanyaan yang dapat mengarahkan siswa fokus pada permasalahan. Artinya, alur berpikir siswa diarahkan hanya tertuju pada eksperimen yang akan dilakukan sehingga diduga berpengaruh dengan keberhasilan membuat hipotesis (Evriani, et.al, 2017).

Aspek KPS terpadu yang mengalami peningkatan yang paling rendah adalah pada aspek melakukan percobaan yaitu hanya sejauh 0,09. Kecilnya peningkatan yang dialami aspek melakukan percobaan karena kurang terbiasanya siswa dalam bereksperimen, sehingga siswa kurang paham menggunakan alat yang mana mengakibatkan hasil pengukuran kurang akurat (Evriani, et.al, 2017).

Analisis instrumen nontes yang dikaji ialah lembar observasi dan lembar skala sikap. Untuk kesederhanan, rekapitulasi kedua data nontest tersebut disajikan pada Tabel 3 dan Tabel 4.

Tabel 3. Rekapitulasi Kegiatan Selama Pembelajaran LoI

\begin{tabular}{cccc}
\hline $\begin{array}{c}\text { Aktivitas } \\
\text { Guru }\end{array}$ & Interpretasi & $\begin{array}{c}\text { Aktivitas } \\
\text { Siswa }\end{array}$ & Interpretasi \\
\hline Semua & & Semua & \\
kegiatan & Baik & kegiatan & Baik \\
guru yang & Sekali & $\begin{array}{c}\text { siswa yang } \\
\text { terlaksana }\end{array}$ & Sekali \\
terlaksana & & $(94 \%)$ & \\
$(100 \%)$ & & & \\
\hline
\end{tabular}

Tabel 4. Rekapitulasi Sikap siswa terhadap LoI

\begin{tabular}{cc}
\hline Aspek Skala Sikap & Respon \\
\hline Antusias siswa terhadap model & Positif \\
LoI $(81 \%)$ & Positif \\
$\begin{array}{c}\text { Aspek KPS terpadu }(80,4 \%) \\
\text { Kemampuan dalam } \\
\text { pembelajaran }(86,7 \%)\end{array}$ & Positif \\
\hline Rata-rata & $82,7 \%$ \\
\hline
\end{tabular}

Pada Tabel 3 menunjukan hampir seluruh siswa aktif di dalam kelas saat guru memberikan pembelajaran dengan model LoI sedangkan respon yang diberikan oleh sebagian besar siswa terhadap model LoI adalah positif.

Deskripsi pada Tabel 4 menunjukan $81 \%$ siswa antusias dalam mengikuti pelajaran, $80,4 \%$ siswa dapat menerapkan aspek KPS terpadu, dan $86,7 \%$ siswa mampu dalam mengerjakan tugas yang 
diberikan oleh guru. Jika dikalkulasikan, maka diperoleh rata-rata respon siswa terhadap model LoI mencapai $82,7 \%$ dengan kategori positif.

Meskipun hasil penelitian menunjukkan peningkatan aspek KPS, peneliti menyadari bahwa penelitian ini masih harus disempurnakan karena terdapat beberapa rekomendasi untuk penelitian selanjutnya. Pada penelitian ini ditemukan beberapa siswa yang masih sulit melakukan percobaan dan kondisi kelas yang kurang kondusif, maka untuk peneliti selanjutnya diharapkan dapat menguasai kelas sehingga ketika melakukan percobaan siswa menjadi lebih tenang dan peneliti akan lebih mudah dalam mengawasi dan mengambil data.

\section{SIMPULAN DAN SARAN}

Berdasarkan analisis data terhadap peningkatan keterampilan proses sains (KPS) terpadu siswa maka dapat disimpulkan bahwa model levels of inquiry (LoI) dapat meningkatkan aspek KPS terpadu dengan $n$-gain sebesar 0,31 (sedang) dan respon siswa terhadap model LoI rata-rata sebesar $82,7 \%$ dengan kategori positif. Hal ini diperkuat dengan data pendukung lembar observasi LoI dimana keputusan/kategori berada pada status "semua kegiatan terlaksana" (untuk guru dan siswa) dengan interpretasi "baik sekali"

\section{DAFTAR PUSTAKA}

Abdurrahman. (2017). Efektivitas dan Kendala Pembelajaran Sains Berbasis Inkuiri terhadap Capaian Dimensi Kognitif Siswa: Meta Analisis. Tadris: Jurnal Keguruan Dan Ilmu Tarbiyah, 2(1), 1-9. https://doi.org/10.24042/tadris.v2i1.1 206

Ambarsari, W., Santosa, S., \& Maridi. (2013). Penerapan Pembelajaran Inkuiri Terbimbing Terhadap Keterampilan Proses Sains Dasar
Pada Pelajaran Biologi Siswa Kelas VIII SMP Negeri 7 Surakarta. Jurnal Pendidikan Biologi, 5(1), 81-95.

Dewi, P. S. (2016). Perspektif Guru sebagai Implementasi Pembelajaran Inkuiri Terbuka dan Inkuiri Terbimbing terhadap Sikap Ilmiah dalam Pembelajaran Sains. Tadris: Jurnal Keguruan Dan Ilmu Tarbiyah, 1(2), 179-186.

Erlinda, N. (2016). Penerapan Metode Pembelajaran Inkuiri Disertai Handout: Dampak Terhadap Hasil Belajar Fisika Siswa SMAN 1 Batang Anai Padang Pariaman. Jurnal Ilmiah Pendidikan Fisika AlBiruni, 5(2), 223-231. https://doi.org/10.24042/jpifalbiruni. v5i2.122

Ertikanto, C. (2017). Perbandingan Kemampuan Inkuiri Mahasiswa Pendidikan Guru Sekolah Dasar dalam Perkuliahan Sains. Jurnal Ilmiah Pendidikan Fisika Al-Biruni, 6(1), 95-102. https://doi.org/10.24042/jpifalbiruni. v6i1.1582

Evriani, Kurniawan, Y., \& Muliyani, R. (2017). Peningkatan Keterampilan Proses Sains (KPS) Terpadu Melalui Penerapan Model Pembelajaran Guided Inquiry Dengan Strategi Student Generated Respresentation (SGRS). Jurnal Ilmiah Pendidikan Fisika Universitas Muhammadiyah Metro, 5(2), 119-125.

Irwandani, I. (2014). Multi Representasi sebagai Alternatif Pembelajaran dalam Fisika. Jurnal Ilmiah Pendidikan Fisika Al-BiRuNi, 3(1), 39-48.

Irwandani, I., \& Rofiah, S. (2015). Pengaruh Model Pembelajaran Generatif Terhadap Pemahaman Konsep Fisika Pokok Bahasan Bunyi Peserta Didik MTs Al-Hikmah Bandar Lampung. Jurnal Ilmiah Pendidikan Fisika Al-Biruni, 4(2), 165-177. 
https://doi.org/10.24042/jpifalbiruni. v4i2.90

Komikesari, H. (2016). Peningkatan Keterampilan Proses Sains dan Hasil Belajar Fisika Siswa pada Model Pembelajaran Kooperatif Tipe Student Team Achievement Division. Tadris: Jurnal Keguruan Dan Ilmu Tarbiyah, 1(1), 15-22.

Latifah, S., Setiawati, E., \& Basith, A. (2016). Pengembangan Lembar Kerja Peserta Didik (LKPD) Berorientasi Nilai-Nilai Agama Islam melalui Pendekatan Inkuiri Terbimbing pada Materi Suhu dan Kalor. Jurnal Ilmiah Pendidikan Fisika Al-Biruni, 5(1), 43-51. https://doi.org/10.24042/jpifalbiruni. v5i1.104

Lindsey, B. A., Hsu, L., Sadaghiani, H., Taylor, J. W., \& Cummings, K. (2012). Positive attitudinal shifts with the physics by inquiry curriculum across multiple implementations. Physical Review Special Topics - Physics Education Research, 8(1), 1-8. https://doi.org/10.1103/PhysRevSTP ER.8.010102

Loverude, M. E., Gonzalez, B. L., \& Nanes, R. (2011). Inquiry-based course in physics and chemistry for preservice K-8 teachers. Physical Review Special Topics - Physics Education Research, 7(1), 1-18. https://doi.org/10.1103/PhysRevSTP ER.7.010106

Malik, A., Y. Kurnia, E., \& S. Robiatus, S. (2016). Peningkatan Keterampilan Proses Sains Siswa melalui Context Based Learning. Jurnal Penelitian Dan Pengembangan Pendidikan Fisika, 2(1), 23-30.

Rismawati, Sinon, I. L. S., Yusuf, I., \& Widyaningsih, S. W. (2017). Penerapan Model Pembelajaran Inkuiri Terbimbing (Guided Inquiry) terhadap Keterampilan Proses Sains Peserta Didik di SMK Negeri 02
Manokwari. Jurnal Pendidikan, 8(1), $12-25$.

Sasmita, P. R. (2017). Penerapan Metode Inkuiri Terbimbing Menggunakan Media kit fisika: Upaya Meningkatkan Aktivitas dan Hasil Belajar Fisika Siswa. Jurnal Ilmiah Pendidikan Fisika Al-Biruni, 6(1), 95-102.

Smallhorn, M., Young, J., Hunter, N., \& Burke da Silva, K. (2015). Inquirybased Learning to Improve Student Engagement in a Large First Year Topic. Student Success, 6(2), 65-71. https://doi.org/10.5204/ssj.v6i2.292

Yusuf, M., \& Wulan, A. R. (2015). Penerapan Model Pembelajaran Discovery Learning Menggunakan Pembelajaran Tipe Shared dan Webbed untuk Meningkatkan Keterampilan Proses Sains. Jurnal Penelitian Dan Pengembangan Pendidikan Fisika, 1(2), 19-26. 